\title{
A rapid MMP-8 bedside test for the detection of intra-amniotic inflammation identifies patients at risk for imminent preterm delivery
}

\author{
Jyh Kae Nien, MD, ${ }^{a}$ Bo Hyun Yoon, MD, PhD, ${ }^{b}$ Jimmy Espinoza, MD, ${ }^{\text {a,c }}$ Juan Pedro \\ Kusanovic, MD, ${ }^{a}$ Offer Erez, MD, ${ }^{a}$ Eleazar Soto, MD, ${ }^{a}$ Karina Richani, MD, ${ }^{a}$ \\ Ricardo Gomez, MD, ${ }^{d}$ Sonia Hassan, MD, ${ }^{c}$ Moshe Mazor, MD, ${ }^{\mathrm{e}}$ \\ Sam Edwin, PhD, ${ }^{a}$ Ray Bahado-Singh, MD, ${ }^{c}$ Roberto Romero, MD ${ }^{a, f}$
}

Perinatology Research Branch, ${ }^{\mathrm{a}}$ NICHD/NIH/DHHS, Bethesda, MD, and Detroit, MI; Department of Obstetrics and Gynecology, Seoul National University College of Medicine, ${ }^{\mathrm{b}}$ Seoul, Korea; Department of Obstetrics and Gynecology, Wayne State University/Hutzel Women's Hospital, ${ }^{\mathrm{c}}$ Detroit, MI; Center for Perinatal Diagnosis and Research (CEDIP), Sótero del Río Hospital, P. Universidad Católica de Chile, ${ }^{\mathrm{d}}$ Puente Alto, Chile; Soroka Medical Center, Ben Gurion University of the Negev, ${ }^{\mathrm{e}}$ Beer Sheva, Israel; Center for Molecular Medicine and Genetics, Wayne State University, ${ }^{\mathrm{f}}$ Detroit, $M I$

Received for publication March 10, 2006; revised May 31, 2006; accepted June 15, 2006

\author{
KEY WORDS \\ MMP-8 \\ Point-of-care test \\ Matrix \\ metalloproteinase \\ Preterm labor \\ Intact membranes \\ Intra-amniotic \\ infection/ \\ inflammation \\ Chorioamnionitis \\ Prematurity
}

\begin{abstract}
Objective: Matrix metalloproteinase- 8 (MMP-8) is an enzyme that is released during neutrophil activation. MMP-8 amniotic fluid concentrations are elevated not only in patients with intra-amniotic infection, but also in patients with negative amniotic fluid cultures who deliver preterm neonates. The objective of this study was to determine whether the results of a rapid MMP-8 bedside test predict imminent preterm delivery. This test can be performed in 15 minutes and without laboratory equipment.

Study design: Amniotic fluid was retrieved from 331 patients admitted with increased preterm uterine contractions and intact membranes who met the inclusion criteria. Amniotic fluid was processed for microbial cultures, Gram stain, glucose concentration, and white blood cell count. Amniotic fluid samples were stored, and the MMP-8 rapid test was performed after delivery. End points included spontaneous preterm delivery within 48 hours, 7 days, and 14 days. Diagnostic indices, predictive values, and likelihood ratios were calculated.

Results: The prevalence of spontaneous preterm delivery within 48 hours, 7 days, and 14 days was $11.6 \%(38 / 327), 20.2 \%(66 / 327)$, and $24.5 \%(80 / 327)$, respectively (4 patients with
\end{abstract}

Supported in part by the Intramural Research Program of the National Institute of Child Health and Human Development, National Institutes of Health, Department of Health and Human Services.

Conflict of Interest: The test described in this article is the subject of a patent application by the Seoul National University in Seoul, Korea. Dr Bo Yoon, one of the coauthors and a professor at the Seoul National University, is listed as an inventor in this patent.

Presented at the 26th Annual Meeting of the Society for Maternal-Fetal Medicine, January 30-February 4, 2006, Miami, FL.

Reprints not available from the authors. Address correspondence to: Roberto Romero, MD, Perinatology Research Branch, NICHD, NIH, DHHS, Wayne State University/Hutzel Women's Hospital, 3990 John R, Box 4, Detroit, MI 48201.

E-mail: warfiela@mail.nih.gov 
augmentation of labor were excluded). A positive MMP-8 rapid test had a positive predictive value of $70 \%(23 / 33)$ for the identification of patients who delivered spontaneously within 48 hours, and 94\% (31/33) for patients who were delivered within 7 days and 14 days (likelihood ratios: 17.5 [95\% CI, 9-33.9], 61.3 [95\% CI, 15.1-250], and 50 [95\% CI, 12-196], respectively).

Conclusion: The MMP-8 rapid test can identify patients at risk for preterm delivery within 7 days and 14 days. Moreover, a positive MMP-8 rapid test result can identify patients with intraamniotic infection/inflammation with a high sensitivity and specificity. This rapid test will give clinicians a fast and accurate assessment of the inflammatory status of the amniotic cavity and allow for better identification of patients at risk for impending preterm delivery.

(C) 2006 Mosby, Inc. All rights reserved.

Intra-amniotic infection/inflammation is causally linked to preterm labor/delivery and fetal injury. ${ }^{1-5}$ Intra-amniotic infection (IAI) is a risk factor for impending preterm delivery, ${ }^{1,2}$ spontaneous rupture of membranes, ${ }^{6-8}$ clinical chorioamnionitis, ${ }^{2}$ and adverse short- and long-term neonatal outcome. , $^{2,9-12}$ The traditional method for the detection of infection is isolation of microorganisms from amniotic fluid (AF). However, this requires time, and results may not be available for appropriate patient treatment. Recent evidence has demonstrated that patients with intra-amniotic inflammation, but a negative AF culture, have a similar outcome to patients with a positive AF culture. ${ }^{13,14}$ Therefore, the detection of inflammation may be more practical than the detection of infection in patient management. Currently, the diagnosis of intra-amniotic inflammation requires a laboratory test.

Recently, a bedside test has been developed to detect intra-amniotic inflammation that is based on the detection of an elevated concentration of matrix metalloproteinase-8 (MMP-8) in AF. The selection of MMP-8 was based on previous studies performed with standard enzyme-linked immunosorbent assay (ELISA) techniques. ${ }^{14,15}$ The configuration of the MMP-8 PTD (preterm delivery) Check test (SK Pharma Co, Ltd, Kyunggi-do, Korea) is similar to a rapid pregnancy test (Figure 1). It requires $20 \mu \mathrm{L}$ of $\mathrm{AF}$ and no laboratory equipment, and the results are available within 15 minutes. This test has a sensitivity of $95 \%$ and a specificity of $93 \%$ in the detection of intra-amniotic inflammation among patients with spontaneous preterm labor and intact membranes. ${ }^{16}$ This study was designed to determine the diagnostic indices, predictive values, efficiency and likelihood ratios of the MMP-8 PTD Check test for the detection of IAI, intraamniotic inflammation, spontaneous preterm delivery, and severe neonatal morbidity.

\section{Methods}

\section{Study population}

Patients admitted between January 1998 and October 2003 to the Sotero del Rio Hospital (Santiago, Chile) with the diagnosis of increased uterine contractility and intact membranes were asked to participate in a prospective cohort study that was designed to examine the relationship between clinical, biochemical, and biophysical parameters and the risk of preterm delivery. The inclusion criteria were (1) singleton gestation, (2) a live fetus whose gestational age was between 22 and 35 weeks, (3) cervical dilation of $\leq 3 \mathrm{~cm}$ by digital examination, (4) intact membranes, and (5) a signed informed consent that had been approved by the Institutional Review Boards of both the Sotero del Rio Hospital and the National Institute of Child Health and Human Development (NIH/DHHS). The study procedures and clinical management are described in the supplemental material to the article.

\section{Sample collection and MMP-8 PTD Check rapid test}

AF was transported to the laboratory in a capped plastic syringe and cultured for aerobic and anaerobic bacteria and genital Mycoplasmas. A white blood cell count, glucose concentration, and Gram stain for microorganisms were performed in AF immediately after collection. The remaining sample was stored at $-70^{\circ} \mathrm{C}$. Details about the MMP-8 PTD Check, MMP-8, and interleukin-6 (IL-6) determinations by ELISA are available in the supplemental material.

\section{Study outcomes}

Primary outcome variables were the occurrence of spontaneous preterm delivery (within 48 hours, 7 days, and 14 days of admission), the presence of a positive AF culture, and AF inflammation (defined as an AF IL-6 concentration of $\geq 2.6 \mathrm{ng} / \mathrm{mL}$ ). ${ }^{13}$ Secondary outcomes included spontaneous preterm delivery at $\leq 32$ weeks of gestation, at $\leq 34$ weeks of gestation, and composite neonatal morbidity (defined as the presence of any of the following conditions: respiratory distress syndrome, suspected or proven neonatal sepsis, pneumonia, bronchopulmonary dysplasia, intraventricular hemorrhage, periventricular leukomalacia, and necrotizing enterocolitis). The statistical analysis is described in the supplemental material. 
(+)

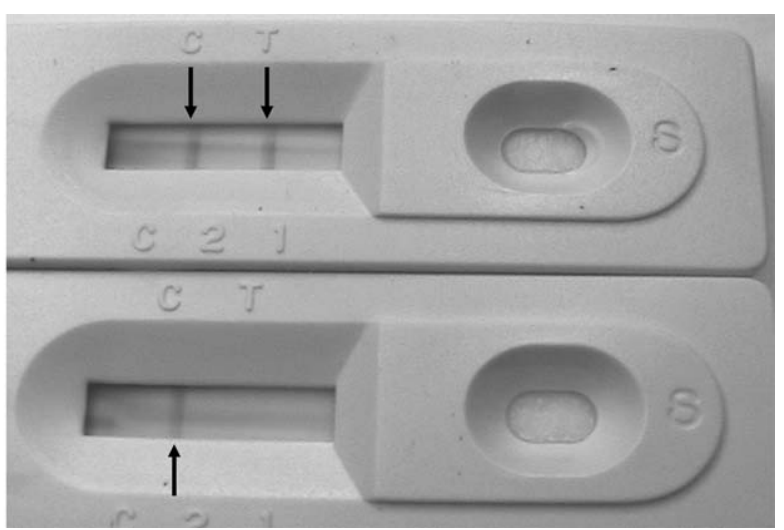

Figure 1 The MMP-8 PTD Check test was considered positive when 2 dark bands were visible, corresponding to the control $(C)$ and testing $(T)$ channels of the kit (arrows).

\section{Results}

\section{Study population}

Over the study period, 331 patients met the inclusion criteria. An MMP-8 PTD Check test was performed in all AF samples. Table I shows the clinical characteristics of the study population. The prevalence of IAI, intraamniotic inflammation, and preterm delivery $(<37$ weeks of gestation) were $7.3 \%(24 / 331), 11.5 \%$ (38/ 331 ), and $41.1 \%(136 / 331)$, respectively. Four patients received augmentation and were excluded from further analysis. The prevalence of spontaneous preterm delivery within 48 hours, 7 days, and 14 days was $11.6 \%$ (38/327), 20.2\% (66/327), and $24.5 \%(80 / 327)$, respectively. Tocolysis was used in $62.8 \%(208 / 331)$ of the population, and a positive MMP-8 rapid test result was detected in $11 \%$ of the cases $(36 / 331)$. Table II displays the microorganisms that were isolated from the AF of patients with IAI. The most frequent isolate was Ureaplasma urealyticum.

\section{MMP-8 rapid test and ELISA agreement}

There was nearly perfect agreement ${ }^{17}$ between the MMP-8 PTD Check and the results of the AF MMP-8 concentrations as determined by ELISA (Kappa, 0.87; $P<.001)$.

\section{MMP-8 PTD Check in the identification of IAI and intra-amniotic inflammation}

The efficiency of a positive MMP-8 rapid test result in the identification of IAI and intra-amniotic inflammation was $94 \%(311 / 331)$ and $97 \%(321 / 331)$, respectively. Table III displays the prevalence, diagnostic indices, predictive values, and likelihood ratios of a positive MMP-8 rapid test in the identification of IAI and inflammation in the study population.
Table I Clinical characteristics of the study population

\begin{tabular}{|c|c|}
\hline Characteristic & $\begin{array}{l}\text { Preterm labor and intact } \\
\text { membranes }(n=331)\end{array}$ \\
\hline Maternal age $(y)^{*}$ & $25 \pm 7$ \\
\hline Gestational age at admission (wk)* & $32 \pm 2$ \\
\hline $\begin{array}{l}\text { Microbial invasion of the amniotic } \\
\text { cavity }(\%)^{\dagger}\end{array}$ & $7.3(24 / 331)$ \\
\hline Gestational age at delivery (wk)* & $36 \pm 3$ \\
\hline $\begin{array}{l}\text { Delivery at }<37 \text { weeks of } \\
\text { gestation }(\%)^{\dagger}\end{array}$ & $41.1(136 / 331)$ \\
\hline
\end{tabular}

Table II Type of microorganisms that were retrieved from AF samples

\begin{tabular}{ll}
\hline Microorganism & $\begin{array}{l}\text { Positive AF culture } \\
(\mathrm{n}=24)^{*}\end{array}$ \\
\hline Ureaplasma urealyticum & $45.8(11 / 24)$ \\
Mycoplasma hominis & $29.2(7 / 24)$ \\
Candida species & $12.5(3 / 24)$ \\
Group B streptococci & $8.3(2 / 24)$ \\
Gram-negative bacilli & $4.2(1 / 24)$ \\
Gram-positive bacilli & $4.2(1 / 24)$ \\
Prevotella species & $4.2(1 / 24)$ \\
Listeria monocytogenes & $4.2(1 / 24)$ \\
\hline
\end{tabular}

Values are given as percentage (proportion).

* Some AF cultures yielded more than 1 microorganism.

\section{MMP-8 PTD Check in the identification of patients at risk for impending preterm delivery}

The prevalence, diagnostic indices, predictive values, and likelihood ratios (positive and negative) in the identification of patients delivered within 48 hours, 7 days, 14 days and at $<32$ and $<34$ weeks of gestation are displayed in Table IV. The efficiency of a positive MMP-8 rapid test in the identification of patients delivered within 48 hours, 7 days, 14 days and at $<32$ and $<34$ weeks of gestation was $92.4 \%(302 / 327)$, $88.7 \%$ (290/327), 84.4\% (276/327), 88.8\% (135/152), and $86 \%(234 / 272)$, respectively.

\section{Results of MMP-8 PTD Check and interval-to-delivery}

Survival analysis indicated that patients with a positive MMP-8 rapid test result had a significantly shorter amniocentesis-to-delivery interval than patients with a negative MMP-8 rapid test result (mean, 3 days [95\% CI, 1-4 days] vs 41 days [95\% CI, 38-44 days]; log rank, $P<.001$; Figure 2). Cox proportional modeling, adjusted for cervical length, tocolysis, antibiotic administration, and gestational age at amniocentesis, indicated that this result remained significant after being controlled for these covariates (hazard ratio: 12.43; 95\% CI, 7.5-20.5). 
Table III Diagnostic indices, predictive values, and likelihood ratios of MMP-8 PTD Check results for the detection of IAI and inflammation

\begin{tabular}{llllllll}
\hline & $\begin{array}{l}\text { Prevalence } \\
(\%)\end{array}$ & $\begin{array}{l}\text { Sensitivity } \\
(\%)\end{array}$ & $\begin{array}{l}\text { Specificity } \\
(\%)\end{array}$ & $\begin{array}{l}\text { Positive } \\
\text { predictive } \\
\text { value (\%) }\end{array}$ & $\begin{array}{l}\text { Negative } \\
\text { predictive } \\
\text { value }(\%)\end{array}$ & $\begin{array}{l}\text { Positive } \\
\text { likelihood ratio } \\
(95 \% \text { CI })\end{array}$ & $\begin{array}{l}\text { Negative } \\
\text { likelihood ratio } \\
(95 \% \text { CI })\end{array}$ \\
\hline $\begin{array}{l}\text { Intra-amniotic } \\
\text { infection* }\end{array}$ & $7.3(24 / 331)$ & $83(20 / 24)$ & $95(291 / 307)$ & $56(20 / 36)$ & $99(291 / 295)$ & $15.9(9.6-26.6)$ & $0.2(0.1-0.3)$ \\
$\begin{array}{l}\text { Intra-amniotic } \\
\text { inflammation }{ }^{\dagger}\end{array}$ & $11.5(38 / 331)$ & $84(32 / 38)$ & $99(289 / 293)$ & $89(32 / 36)$ & $98(289 / 295)$ & $61.7(23.1-164.8)$ & $0.2(0.1-0.4)$ \\
\hline * A positive AF culture for microorganisms. & & & & & & \\
${ }^{\dagger}$ AF IL-6 concentration, $\geq 2.6 \mathrm{ng} / \mathrm{mL}$.
\end{tabular}

Table IV Diagnostic indices, predictive values, and likelihood ratios of MMP-8 PTD Check for the identification of patients with spontaneous preterm delivery within 48 hours, 7 days, 14 days and at $<32$ and $<34$ weeks of gestation*

\begin{tabular}{|c|c|c|c|c|c|c|c|}
\hline & $\begin{array}{l}\text { Prevalence } \\
(\%)^{\dagger}\end{array}$ & $\begin{array}{l}\text { Sensitivity } \\
(\%)^{\dagger}\end{array}$ & $\begin{array}{l}\text { Specificity } \\
(\%)^{\dagger}\end{array}$ & $\begin{array}{l}\text { Positive } \\
\text { predictive } \\
\text { value }(\%)^{\dagger}\end{array}$ & $\begin{array}{l}\text { Negative } \\
\text { predictive } \\
\text { value }(\%)^{\dagger}\end{array}$ & $\begin{array}{l}\text { Positive } \\
\text { likelihood } \\
\text { ratio }(95 \% \text { CI })\end{array}$ & $\begin{array}{l}\text { Negative } \\
\text { likelihood } \\
\text { ratio }(95 \% \mathrm{CI})\end{array}$ \\
\hline $\begin{array}{l}\text { Delivery within } \\
48 \text { hours }\end{array}$ & $11.6(38 / 327)$ & $61(23 / 38)$ & $97(279 / 289)$ & $70(23 / 33)$ & $95(279 / 294)$ & $17.5(9-33.9)$ & $0.4(0.2-0.8)$ \\
\hline $\begin{array}{l}\text { Delivery within } \\
7 \text { days }\end{array}$ & $20.2(66 / 327)$ & $47(31 / 66)$ & $99(259 / 261)$ & $94(31 / 33)$ & $88(259 / 294)$ & $61.3(15.1-250)$ & $0.5(0.1-2.2)$ \\
\hline $\begin{array}{l}\text { Delivery within } \\
14 \text { days }\end{array}$ & $24.5(80 / 327)$ & $39(31 / 80)$ & $99(245 / 247)$ & $94(31 / 33)$ & $83(245 / 294)$ & $50(12-196)$ & $0.6(0.2-2.5)$ \\
\hline $\begin{array}{l}\text { Delivery at } \\
\quad<32 \text { weeks } \\
\text { of gestation }\end{array}$ & $21.1(32 / 152)$ & $56(18 / 32)$ & $98(117 / 120)$ & $86(18 / 21)$ & $89(117 / 131)$ & $22.5(7.1-71.7)$ & $0.5(0.1-1.4)$ \\
\hline $\begin{array}{c}\text { Delivery }<34 \\
\text { weeks of } \\
\text { gestation }\end{array}$ & $22.4(61 / 272)$ & $44(27 / 61)$ & $98(207 / 211)$ & $87(27 / 31)$ & $86(207 / 241)$ & $23.4(8.5-64.2)$ & $0.6(0.2-1.6)$ \\
\hline
\end{tabular}

* Four patients whose condition required augmentation were excluded from this analysis.

${ }^{\dagger}$ Numbers in parentheses represent proportions.

\section{MMP-8 PTD Check results and composite neonatal morbidity}

Severe neonatal morbidity was present in $4.8 \%(16 / 331)$ of the study population, including respiratory distress syndrome (3\% [10/331]), proven neonatal sepsis (1.2\% [4/ $331]$ ), pneumonia (2.4\% [8/331]), bronchopulmonary dysplasia $(1.5 \%$ [5/331]), intraventricular hemorrhage $(0.9 \%$ [3/331]), periventricular leukomalacia $(0.6 \%$ [2/ $331])$, and necrotizing enterocolitis $(0.6 \%$ [2/331]). The prevalence, sensitivity, specificity, positive and negative predictive values, and the likelihood ratios of a positive MMP-8 rapid test in the identification of composite neonatal morbidity are displayed in Table $\mathrm{V}$.

\section{Comment}

\section{Principal findings of the study}

MMP-8 PTD Check is a sensitive and specific test for the identification of both IAI and inflammation among patients with preterm labor and intact membranes. A patient with a positive MMP-8 PTD Check result is at a substantial risk for spontaneous preterm delivery within 48 hours, 7 days, and 14 days, with likelihood ratios of a positive test ranging from 17 to 61 (Table IV).

\section{A point-of-care test for the detection of intra-amniotic inflammation}

Compelling evidence indicates that patients with intraamniotic inflammation are at greater risk for impending preterm delivery and adverse perinatal outcome than patients without intra-amniotic inflammation. ${ }^{13,14,18}$ Moreover, previous studies demonstrated that the pregnancy outcome of women with microbiologically proven IAI is similar to those with intra-amniotic inflammation, but without positive AF cultures for microorganisms. ${ }^{13,14}$ Clinical application requires that a method for the detection of intra-amniotic inflammation be easily available to the clinician for 24-hour testing, hence the need for point-of-care testing.

The College of American Pathologists defines pointof-care testing as "analytical patient testing activities 
Table V Diagnostic indices, predictive values, and likelihood ratios of MMP-8 PTD Check for the identification of composite severe neonatal morbidity

\begin{tabular}{llllllll}
\hline & Prevalence & Sensitivity & Specificity \\
$(\%)$ & $(\%)$ & $\begin{array}{l}\text { Positive } \\
\text { predictive } \\
\text { valuable }\end{array}$ & $\begin{array}{l}\text { vegative } \\
\text { predictive }\end{array}$ & $\begin{array}{l}\text { Positive } \\
\text { value (\%) }\end{array}$ & $\begin{array}{l}\text { Negative } \\
\text { likatio (95\% CI) }\end{array}$ & $\begin{array}{l}\text { (ikelihood } \\
\text { ratio (95\% CI) }\end{array}$ \\
\hline $\begin{array}{c}\text { Composite neonatal } \\
\text { complications }\end{array}$ & $4.8(16 / 331)$ & $63(10 / 16)$ & $92(289 / 315)$ & $28(10 / 36)$ & $98(289 / 295)$ & $7.6(4.5-12.9)$ & $0.4(0.2-0.7)$ \\
\hline
\end{tabular}

provided within the institution, but performed outside the physical facilities of the clinical laboratories. It does not require permanent dedicated space, but instead includes kits and instruments, which are either hand carried or transported to the vicinity of the patient for immediate testing at that site." ${ }^{19,20}$ Point-of-care testing is considered important to increase clinical efficiency and improve medical and economic outcomes. ${ }^{21}$ The MMP-8 PTD Check fulfills most of the criteria proposed to assess an optimal point-of-care testing, ${ }^{19}$ namely: (1) simple testing method, (2) rapid availability of the results (up to 15 minutes), (3) easy interpretation of the results (Figure 1), (4) low maintenance, because the kit can be stored at room temperature, (5) strong correlation with standard laboratory procedures, and (6) low cost, because there is no need for capital equipment and because the market price can be driven by need.

\section{Strength and weakness of the study}

Major strengths of the study are: (1) it includes a large cohort of women with preterm labor and intact membranes in a homogeneous population ( $\mathrm{n}=331$ women); (2) the cohort is not contaminated with patients who have a different rate of IAI and intra-amniotic inflammation, such as those with preterm premature rupture of membranes (PROM). Studies with a mixed population (preterm labor with intact membranes and preterm PROM) may require adjustment for the estimation of predictive values that depend on the prevalence of the disease/conditions; and (3) the test was not used in patient treatment. It could be argued that a weakness of this study is that it was conducted with AF which was stored at $-70^{\circ} \mathrm{C}$. However, validation of the test performed by the biotechnology company before the release of this product indicates substantial agreement between results in fresh and freeze-thawed AF. The optimal treatment of a patient with IAI and/or inflammation and the barriers to clinical research of these particular sets of issues have been discussed elsewhere. ${ }^{22}$

\section{Previous studies of AF MMP-8 concentrations in women with preterm labor and intact membranes}

The results of the current study are consistent with previous reports indicating that an elevated AF MMP-8

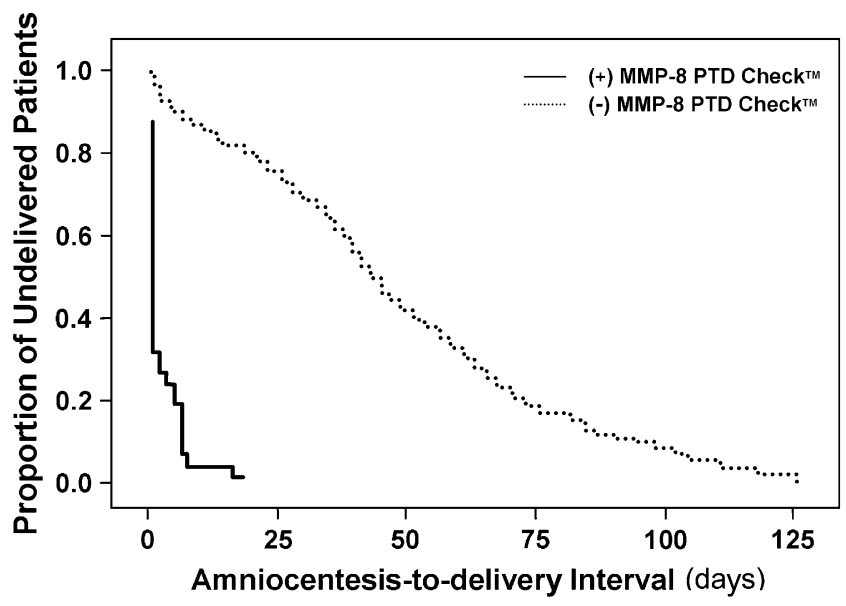

Figure 2 Patients with a positive MMP-8 rapid test result had a significantly shorter amniocentesis-to-delivery interval than patients with a negative MMP- 8 rapid test result (mean, 3 days [95\% CI, $1-4$ days] vs 41 days [95\% CI, 38-44 days], respectively; log rank, $P<.001)$.

concentration is associated with impending preterm delivery, IAI, and severe neonatal morbidity. ${ }^{15,23,24}$

\section{Clinical implication of this study}

There is now compelling evidence that fetal exposure to IAI and inflammation is associated with adverse outcomes that include severe neonatal morbidity, perinatal death, and long-term handicap (such as cerebral palsy and chronic lung disease). Thus, the optimal treatment of patients with preterm labor would require knowledge of whether there is IAI and/or inflammation. The MMP-8 PTD Check test can determine the presence of intra-amniotic inflammation within minutes and does not require laboratory equipment. Follow-up clinical trials are required to determine the role of the MMP-8 rapid test for the identification of intra-amniotic inflammation at the time of amniocentesis, as well as to determine whether, based on the rapid test results, treatment with antibiotics and/or anti-inflammatory agents may improve pregnancy outcome.

\section{References}

1. Romero R, Quintero R, Oyarzun E, Wu YK, Sabo V, Mazor M, et al. Intraamniotic infection and the onset of labor in preterm 
premature rupture of the membranes. Am J Obstet Gynecol 1988; 159:661-6

2. Romero R, Sirtori M, Oyarzun E, Avila C, Mazor M, Callahan $\mathrm{R}$, et al. Infection and labor V: Prevalence, microbiology, and clinical significance of intraamniotic infection in women with preterm labor and intact membranes. Am J Obstet Gynecol 1989;161: 817-24.

3. Yoon BH, Jun JK, Romero R, Park KH, Gomez R, Choi JH, et al. Amniotic fluid inflammatory cytokines (interleukin-6, interleukin1 beta, and tumor necrosis factor-alpha), neonatal brain white matter lesions, and cerebral palsy. Am J Obstet Gynecol 1997;177:19-26.

4. Dammann O, Leviton A. Maternal intrauterine infection, cytokines, and brain damage in the preterm newborn. Pediatr Res 1997; 42:1-8

5. Elovitz MA, Mrinalini C, Sammel MD. Elucidating the early signal transduction pathways leading to fetal brain injury in preterm birth. Pediatr Res 2006;59:50-5.

6. Cassell GH, Davis RO, Waites KB, Brown MB, Marriott PA, Stagno S, et al. Isolation of Mycoplasma hominis and Ureaplasma urealyticum from amniotic fluid at 16-20 weeks of gestation: potential effect on outcome of pregnancy. Sex Transm Dis 1983;10:294-302.

7. Gray DJ, Robinson HB, Malone J, Thomson RB Jr. Adverse outcome in pregnancy following amniotic fluid isolation of Ureaplasma urealyticum. Prenat Diagn 1992;12:111-7.

8. Horowitz S, Mazor M, Romero R, Horowitz J, Glezerman M. Infection of the amniotic cavity with Ureaplasma urealyticum in the mid trimester of pregnancy. J Reprod Med 1995;40:375-9.

9. Gibbs RS, Dinsmoor MJ, Newton ER, Ramamurthy RS. A randomized trial of intrapartum versus immediate postpartum treatment of women with intra-amniotic infection. Obstet Gynecol 1988;72:823-8.

10. Belady PH, Farkouh LJ, Gibbs RS. Intra-amniotic infection and premature rupture of the membranes. Clin Perinatol 1997; 24:43-57.

11. Yoon BH, Romero R, Kim KS, Park JS, Ki SH, Kim BI, et al. A systemic fetal inflammatory response and the development of bronchopulmonary dysplasia. Am J Obstet Gynecol 1999;181: 773-9.

12. Yoon BH, Romero R, Park JS, Kim CJ, Kim SH, Choi JH, et al. Fetal exposure to an intra-amniotic inflammation and the development of cerebral palsy at the age of three years. Am J Obstet Gynecol 2000;182:675-81.
13. Yoon BH, Romero R, Moon JB, Shim SS, Kim M, Kim G, et al. Clinical significance of intra-amniotic inflammation in patients with preterm labor and intact membranes. Am J Obstet Gynecol 2001;185:1130-6.

14. Shim SS, Romero R, Hong JS, Park CW, Jun JK, Kim BI, et al. Clinical significance of intra-amniotic inflammation in patients with preterm premature rupture of membranes. Am J Obstet Gynecol 2004;191:1339-45.

15. Maymon E, Romero R, Chaiworapongsa T, Berman S, Conoscenti G, Gomez R, et al. Amniotic fluid matrix metalloproteinase- 8 in preterm labor with intact membranes. Am J Obstet Gynecol 2001;185:1149-55.

16. Romero R, Gomez R, Nien JK, Yoon BH, Luo R, Beecher C, et al. Metabolomics in premature labor: a novel approach to identify patients at risk for preterm delivery. Am J Obstet Gynecol 2004;191(suppl):S2.

17. Landis JR, Koch GG. The measurement of observer agreement for categorical data. Biometrics 1977;33:159-74.

18. Ghezzi F, Gomez R, Romero R, Yoon BH, Edwin SS, David C, et al. Elevated interleukin- 8 concentrations in amniotic fluid of mothers whose neonates subsequently develop bronchopulmonary dysplasia. Eur J Obstet Gynecol Reprod Biol 1998;78:5-10.

19. Gutierres SL, Welty TE. Point-of-care testing: an introduction. Ann Pharmacother 2004;38:119-25.

20. College of American Pathologists: Commission on Laboratory Accreditation. Point-of-care testing checklist. Northfield (IL) and Washington, DC: College of American Pathologists; 2005.

21. Kost GJ, Tran NK. Point-of-care testing and cardiac biomarkers: the standard of care and vision for chest pain centers. Cardiol Clin 2005;23:467-90.

22. Gomez R, Romero R, Nien JK, Chaiworapongsa T, Medina L, Kim YM, et al. A short cervix in women with preterm labor and intact membranes: a risk factor for microbial invasion of the amniotic cavity. Am J Obstet Gynecol 2005;192:678-89.

23. Maymon E, Romero R, Pacora P, Gomez R, Athayde N, Edwin S, et al. Human neutrophil collagenase (matrix metalloproteinase 8) in parturition, premature rupture of the membranes, and intrauterine infection. Am J Obstet Gynecol 2000;183:94-9.

24. Maymon E, Romero R, Chaiworapongsa T, Kim JC, Berman S, Gomez R, et al. Value of amniotic fluid neutrophil collagenase concentrations in preterm premature rupture of membranes. Am J Obstet Gynecol 2001;185:1143-8. 